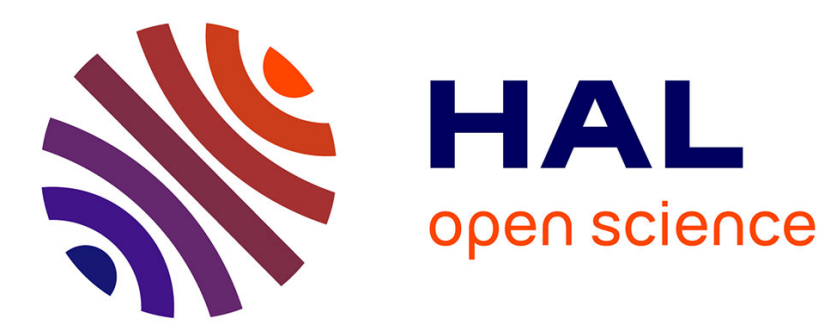

\title{
A Role-Based Maturity Model for Digital Relevance
}

\author{
Katja Bley, Hendrik Schön
}

\section{To cite this version:}

Katja Bley, Hendrik Schön. A Role-Based Maturity Model for Digital Relevance. 18th Conference on e-Business, e-Services and e-Society (I3E), Sep 2019, Trondheim, Norway. pp.738-744, 10.1007/9783-030-29374-1_60. hal-02510129

\section{HAL Id: hal-02510129 \\ https://hal.inria.fr/hal-02510129}

Submitted on 17 Mar 2020

HAL is a multi-disciplinary open access archive for the deposit and dissemination of scientific research documents, whether they are published or not. The documents may come from teaching and research institutions in France or abroad, or from public or private research centers.
L'archive ouverte pluridisciplinaire HAL, est destinée au dépôt et à la diffusion de documents scientifiques de niveau recherche, publiés ou non, émanant des établissements d'enseignement et de recherche français ou étrangers, des laboratoires publics ou privés. 


\title{
A Role-based Maturity Model for Digital Relevance
}

\author{
Katja Bley and Hendrik Schön \\ Business Informatics, esp. IS in Trade and Industry, TU Dresden, Dresden, Germany \\ \{katja.bley, hendrik.schoen\} atu-dresden.de
}

\begin{abstract}
For several decades, maturity models have been regarded as a magic bullet for enterprises' economic growth processes. In these models, domains are structured and divided into (mostly linear) levels that are used as benchmarks for enterprise development. However, this approach has its shortcomings in the context of complex topics like digitalization. As we understand it, digitalization defines a conceptual approach to a phenomenon that is individually important and promising in different ways for different enterprises. Consequently, existing maturity models in their current form are not able to reproduce the full extent of digitalization for enterprises, as the models are too general—especially for SMEs of different sizes and from different sectors. In our research, we propose a maturity model approach that introduces the concept of roles as a possibility to depict enterprises' specific components, which are then added to a static core model. By doing so, the resulting maturity model is more flexible and scalable for SMEs' specific needs. Furthermore, we introduce a new assessment approach for defining whether improving digitalization is truly relevant and worthwhile for the enterprise.
\end{abstract}

Keywords: Maturity Model, Individualization, Digitalization Relevance, Role.

\section{Introduction}

Recent developments, like the digitalization of economic processes, increase the pressure on enterprises of all sizes to adapt and digitally transform in order to remain competitive and efficient. Hence, companies search for tools that can help determine their current benchmarking position or that can assess their subsequent market position compared to a predefined best-practice performance. One famous example of these benchmarking tools is Maturity Models (MMs). An MM is primarily a structured, systematic elaboration of the best practices and processes within a domain that are related to the functioning and structure of an organization. An MM is divided into different levels, which are used as benchmarks for the maturity of an organization. Due to their general applicability and their simple development, many MMs have emerged in both science and practice over the last decade. MMs are especially favored when it comes to the defining, delimiting, and accounting for newly-emerging social or technical phenomena, such as digitalization or Industrial Internet/Industry 4.0 and its impact on enterprises. MMs are also favored for the classification of SMEs, as these companies are financially incapable of undergoing well-coordinated digitalization programs. 
However, despite their wide range of applicability, MMs are not widely known of or implemented. A recent study revealed that scientific and consultancy Industry 4.0MMs are quite unknown in business practice, although potential applicants stated a need for and interest in these models in general [1]. Apparently, if Industry 4.0 is considered a proxy for digitalization, a mismatch exists between the generated benefit of existing MMs and the needs of enterprises. Existing models fail in their ability to depict sector-specific organizational structures and characteristics. The definition/development of maturity level is generalized, vague, or not precise enough to be adapted by SMEs of different business sectors.

By designing a new concept of digital maturity within an MM that adapts to the specific components of a sector, we will be able to describe the benefit to an enterprise of moving along the maturity scale. With the application of this new concept for SMEs' individualization, our role-based relevance MM is able to adapt to specific SME characteristics, representing individual relevance of digital process improvement for each concrete SME.

\section{Maturity Models: Concept and Criticism}

Maturity, as a "state of being complete, perfect or ready" [2], is demonstrated by separating organizational growth process into linear levels. In staged MMs, each of these levels has a pre-defined set of characteristics that represent a certain level of maturity. Only after fulfilling all requirements in one level can a higher level be reached. In continuous MMs, the enterprise's maturity scoring can be executed on different levels. The final maturity score can be the weighted sum of single characteristics on different levels or several maturity levels in different dimensions [3]. The MM focus varies depending on workforce, processes, or management orientation, and on application areas such as software development, HR, and marketing. In addition to the wide range of applicable areas, its relatively rapid development promotes high dissemination.

Numerous best-practice articles exist on the development of MM, as the topic is widely discussed in research [e.g., 4-6]. However, some voices are critical of these somewhat-simplified, methodical, step-by-step development approaches. Pöppelbuß et al. [6], for instance, criticize the lack of an empirical foundation, which often leads to simply copying model structures without considering a conceptual grounding based in literature. Lasrado et al. [7] further criticize the lack of validation for selected variables and appropriate dimensions, as well as the lack of operationalization of maturity measurements. Moreover, they insist that a linear course of maturation must be a prerequisite for creating and applying an MM. The concept of equifinality (which postulates that an outcome can be achieved by more than one path) is rarely considered in MM development. Another critique is the lack of individualized MMs in terms of application and assessment. Taking up this aspect, our research focuses on a more individualized and flexible approach to an MM for digitalization; we consider this phenomenon as multidimensional, which cannot be captured by applying an existing (linear) approach to maturity. In order to meet this demand, we design a new type of MM, applying an empirical development approach and a different understanding of "moving along the 
maturity ladder." As a result, we become able to explain the benefits of improvement per level for distinct business sectors.

\section{Towards a Conceptual Approach for a new Maturity Model}

Considering the above-mentioned shortcomings of existing MMs, we intend to develop a new MM concept approach to measure digitalization, especially in SMEs. Digital transformation is a highly complex but promising process for all business sectors. Nevertheless - due to a variety of possible digitalization processes internal to, external to, and between enterprises of all sectors - the anatomy and individual progress of SME digitalization must be captured. Our research question (RQ), therefore is: how can the concept of an MM be concretized for static characteristics of SMEs (domain, size, and sector) as well as for dynamic components of individual SMEs (achieved and required digitalization conditions)? To answer this RQ, we develop a new MM concept, which evolves from a broad cross-enterprise to an individualized, enterprise-specific focus.

\subsection{The Construction of the Maturity Model Framework}

Due to the dual character of our MM concept, we combine static and dynamic conceptual components (Fig.1). A Core Model unites the foundational concepts of MM (Fig.1 (i)): the maturity scale on the $\mathrm{x}$-axis, the digitalization scale on the $\mathrm{y}$-axis, and the pooling of digitalization-relevant factors for multiple SME sectors and for multiple sizes of a considered domain. A literature analysis and expert interviews may be used to detect digitalization-relevant factors for the pool, as these depend heavily on the practical experience of domain experts. At this stage, the maturity constructs are still unspecific, as the concepts are individualized to the research framework afterwards.

Since allocating concrete factors to maturity levels depends heavily on the sector characteristics of the SME, we utilize the idea of a role. A role is a common concept that has gained attention in the past few decades in multiple disciplines in software engineering but also in organizational modeling [e.g., 8]. In our model, a role specifies the selection and allocation of factors from the pool to the maturity levels in the maturity scale of the Core Model. As a role is utilized to represent a class or sector of enterprises (e.g., a role for the class of "small-sized non-international transport logistic enterprises"), it can be chosen or exchanged depending on the model user's intention. In particular, a user needs to select a role, which specifies the $\mathrm{x}$-axis of the dimension chart. This contains information on the different levels $l$ with the maturity characteristics for the SME. Thus, instead of using the same levels for different kinds of enterprises, the role-based approach allows us to more precisely identify maturity levels, depending on the requirements represented by a role. The levels of an "international logistics" enterprise may differ widely from a "national logistics" enterprise. One possible method for assigning factors from the pool to the maturity levels of a role involves using a set-theoretic approach called Qualitative Comparative Analysis (QCA). This allows multiple combinations of necessary and sufficient conditions to be detected, which lead to a specific outcome (e.g., maturity level of an SME; blank bubbles per 
level (Fig.1 (ii)). A similar approach was taken by [9], who used set theory to create an MM. However, the role only has static information about the SME with regard to the level structure. Enterprise-specific information (such as the factors' fulfillment or the current level of the SME) are determined in the subsequent individualization (Fig.1 (iii)).

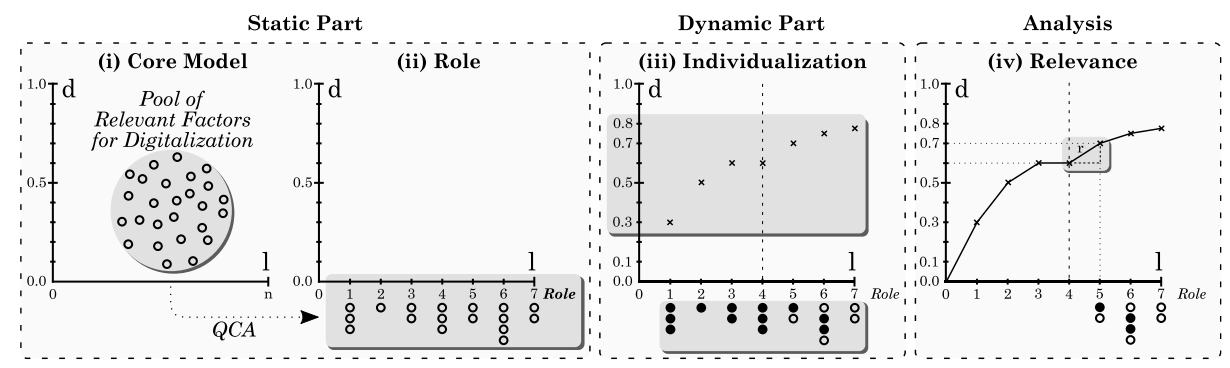

Fig. 1. Procedure model for the application and instantiation of the role-oriented MM.

\subsection{The Individualization of the Maturity Model}

The individualization of the MM (Fig.1 (iii)) represents the dynamic part of our MM, as it directly involves the user (SME) of the model. After the user has selected their corresponding role, the instantiated model appears with the predefined factors at the respective level (Fig.1 (ii)). Through user interviews and questionnaires, the SME is asked to specify its current equipment and development status. With this step, the already-fulfilled digitalization-related conditions, techniques, and processes (= factors) are queried and recorded in the X-axis of the model (Fig.1 (iii), filled bubbles). The level reached by the SME is the highest level at which all factors are fulfilled (e.g., level 4 in Fig.1 (iii)).

The individualized MM consists of the influence and calculation of a digitalization quotient $d$ on the y-axis. It is determined by surveys on additional, not-yet-digitalized, enterprise-specific processes, deriving digitalization potential for possible improvement steps for the SME. The gradient is an abstraction of the enterprise's fulfillment of the targeted digitalization maturity levels. It relates the processes of the respective level to the overall digitalization processes of the enterprise (mapped between 0 and 1). A maturity curve is created by combining the digitalization quotients of the levels.
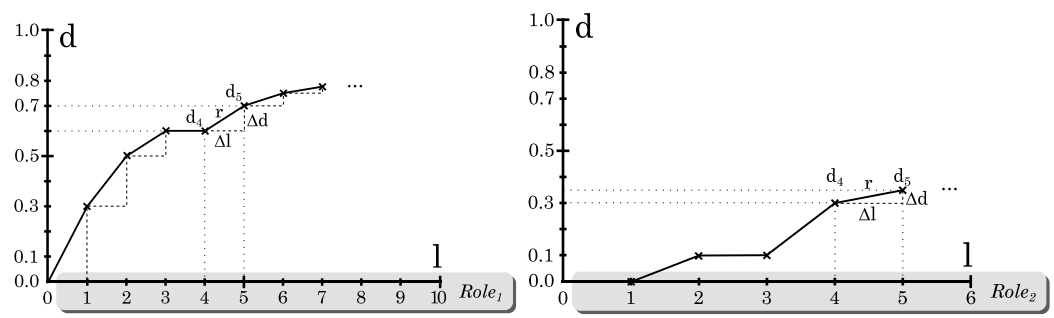

Fig. 2. Two domain-specific MMs, instantiated with different roles. 
Thus, the increase of maturity between the levels reflects a relevance $r$ of the SME's individual digitalization. This depends on the applied role as well as on the individual calculated digitalization quotient $d$ per level (Fig.2).

\subsection{The Concept of Digitalization Relevance}

The $y$-axis represents a scale for the value range of our metric, digitalization quotient $d$, which ranges from 0 to 1 . The quotient expresses the degree to which the aggregation of the current and previous maturity levels affects the enterprise's digitalization. A high quotient can be understood as indicating that many processes have already benefited from digitalization on this maturity level, while a low quotient means that the enterprise has only marginally benefited from the levels achieved so far. The quotient is generally determined by the ratio of the sum of already-digitalized processes in current and previous levels with the total number of processes in the enterprise that can be digitalized:

$$
d_{l}=\frac{\sum_{i=1}^{l}\left(p_{i}\right)}{p_{n}}
$$

where $l$ is the approached level and $n$ is the total number of maturity levels. However, the concrete mathematical calculation is still being researched. We could include, for example, process complexity with different weights. However, this is not the focus of this short paper. The plotting of the quotient $d$ on the x-axis results in a monotonously increasing curve. Thus, calculating the derivation of the curve between two levels indicates the digitalization relevance,

$$
r=\frac{\Delta d}{\Delta l}
$$

According to our understanding, relevance - as significance or meaningfulness - is a "complex but systematic and measurable concept if approached conceptually and operationally from the user's perspective" [10]. We incorporate this concept into our MM as we conceptually design the model and involve the SME's characteristics in creating the maturity path.

By the progression of the resulting curve, the maturity path for an SME is determined, and it represents the decisive component of the resulting MM. The relevance $r$ defines the individual benefit of an SME moving from one maturity level to the next. Applied to the interpretation of the model, the derivation is an indicator of the relevance of digitalizing additional processes in an SME. With decreasing relevance (compared to the previous $r$ ), the enterprise can decide whether it is reasonable and profitable to digitize upcoming processes, in relation to costs/expenses/time to be invested. Since the curve - and, accordingly, the derivation - can vary in its significance, the relevance for each SME is unique. Thus, different SMEs may have different relevance values while achieving the same maturity level with identical roles. However, different SMEs can still be compared by the maturity level of their current relevance in digitalization.

The above-mentioned approach for a single, domain-specific MM can be extended to other domains by following the development approach, which will also be elaborated upon as part of our research (method artefact). 


\section{Contribution and Future Work}

The top-down conceptual MM approach introduced here, from coarse orientation (core model) to an individualized focus (role and relevance orientation), allows for better assessment of digitalization for a decisive SME. Our concept would allow maturity to be graphically and arithmetically demonstrated, taking process path dependencies into account. It reveals up to which point it is reasonable for an SME to continue to digitalize itself. Contrary to the current trend of "the more digitalization, the better", our MM offers the opportunity to give concrete instructions to enterprises from different industries and sectors, taking their individual situations into consideration.

The next research steps will focus on a prototype of a domain-specific MM. We intend to define the desired domain and to conduct a literature analysis and expert interviews concerning the domain's digitalization-relevant business processes (factor pool). After that, the digitalization quotient formula must be refined to take into account the corresponding processes of the enterprises and their characteristics. Furthermore, we will construct a representative role, with its specific relevant factors, out of the pool. We will apply QCA to determine their assignment and maturity order, and we will test our digitalization algorithm in concrete SMEs. Several iterations and evaluations will help improve the formula and its impact for guided digitalization within SMEs.

\section{References}

1. Felch, V., Asdecker, B., Sucky, E.: Maturity Models in the Age of Industry 4.0 - Do the Available Models Correspond to the Needs of Business Practice? In: Proc. 52nd Hawaii Int. Conf. Sys. Sciences (HICSS). pp. 5165-5174.

2. Simpson, J.A., Weiner, E.S.C.: The Oxford English dictionary. Clarendon Press, Oxford (1989).

3. Lahrmann, G., Marx, F., Mettler, T., Winter, R., Wortmann, F.: Inductive Design of Maturity Models: Applying the Rasch Algorithm for Design Science Research. 6629 LNCS, 176-191 (2011).

4. De Bruin, T., Freeze, R., Kaulkarni, U., Rosemann, M.: Understanding the Main Phases of Developing a Maturity Assessment Model. In: 16th Australasian Conf. on Inf. Sys. (ACIS). Sydney (2005).

5. Becker, J., Knackstedt, R., Pöppelbuß, J.: Developing maturity models for IT management. Business \& Information Systems Engineering. 1, 213-222 (2009).

6. Pöppelbuß, J., Röglinger, M.: What Makes a Useful Maturity Model? A Framework of General Design Principles for Maturity Models and Its Demonstration in Business Process Management. ECIS 2011 Proc. Helsinki (2011).

7. Lasrado, L., Vatrapu, R., Andersen, K.: Maturity Models Development in IS Research: A Literature Review. Proc. 38th Inf. Sys. Research Seminar, Scandinavia (IRIS 38). 6, (2015).

8. Bera, P., Burton-Jones, A., Wand, Y.: Improving the representation of roles in conceptual modeling: theory, method, and evidence. Requirements Eng. 23(4), 465-491 (2017).

9. Lasrado, L., Vatrapu, R., Andersen, K.: A Set Theoretical Approach to Maturity Models: Guidelines and Demonstration. In: Proc. 37th Int. Conf. on Inf. Sys. ICIS. Dublin (2016).

10. Schamber, L., Eisenberg, M.B., Nilan, M.S.: A Re-Examination of Relevance: Toward a Dynamic, Situational Definition. Inf. Processing \& Management. 26, 755-776 (1990). 